\title{
Dealing with inappropriate advances from patients
}

\author{
Adnan Ali, 4th year medical student
}

\section{PREAMBLE}

As responsible clinicians we remain vigilant in maintaining a professional doctor-patient relationship. Indeed, the art of consultation involves establishing a good rapport with the patient, to enable them to share sensitive information, which allows us to provide appropriate care. In most cases, the patient is aware and respects the boundaries within this relationship and welcomes the confidentiality that it holds. Albeit, during our clinical practice there will be situations where the patient knowingly or unknowingly breaches the boundary. Here I discuss one such real-life occurrence and outline recommendations for future practice.

\section{SCENARIO}

The scenario takes place in a general practice consultation and involves a female doctor (GP) and a male patient (M) in their sixties. I was a passive observer, acting within my role as a medical student, during this consultation.

$M$ presented with back pain and was asked to describe the exact location of his pain. $M$ suddenly stood up and leaned in with both hands towards the doctor's lower back region. GP immediately retreated back and authoritatively told $M$ to take a seat and point to the location on himself. Throughout the consultation, $M$ also made several attempts to shift the focus of the conversation, to the doctor's personal life while divulging unnecessary details about his own.

During the physical examination, GP ensured that I was present as a chaperone and wore gloves throughout to reinforce a professional distance between the doctor and patient.

\section{ISSUES TO CONSIDER FROM THE SCENARIO}

There are several issues to consider. Firstly, GP has a right to her personal space and should feel comfortable in her work environment.

Secondly, if I was not present in the room and GP was slow to react, it places her in a compromising position. The scenario can be misinterpreted by another member of staff if they inadvertently walked in. Alternatively, $M$ could put a false complaint in, stating that GP asked him to touch her lower back.

Finally, if such advances are not appropriately dealt with immediately, it will lead to a breakdown of the professional doctor-patient relationship. As mentioned in Good Medical Practice, ${ }^{1}$

"Trust is the foundation of the doctor-patient partnership. Patients should be able to trust that their doctor will behave professionally towards them during consultations and not see them as a potential sexual partner."

\section{RECOMMENDATIONS}

GMC's Good Medical Practice ${ }^{1}$ states,

"If a patient pursues a sexual or improper emotional relationship with you, you should treat them politely and considerately and try to re-establish a professional boundary."

Here are my recommendations to put this guidance into practice.

1. Have a lower threshold to request a chaperone. Do not assume chaperones are only needed for intimate examinations.

2. Wearing gloves, just as GP did in this scenario, is a good tactic to maintain a professional distance.

3. Let your previous consultations with that patient guide you.

4. Trust your gut instincts.

5. Document the nature of any advances to pre-warn other clinicians to remain vigilant and to protect your own practice. Consider sharing with another peer to have their support if allegations arise against you in the future.

6. Share similar experiences with colleagues to help them develop their own strategies in dealing with such situations.

7. Have a premediated and rehearsed strategy to counter physical and verbal advances from patients. Switching to an authoritative vocal tonality is likely to be more effective.

a. Verbal advances may be stemmed by a phrase like "I need to ask you more questions specific to your medical problem, so we will have to stop talking about personal matters now". Then one should proceed with more close-ended questions.

b. Physical advances can be countered as done so by GP in the above scenario. Some clinics have an alarm button under the desk or on the computer which one should be familiar with.

8. Medical schools should consider incorporating these scenarios into communication skill sessions with actors to better prepare students for future clinical practice.

9. Hospitals and general practices can organise communication workshops with a focus on dealing with such situations.

If all else fails then it is best to end the professional relationship, one should follow these measures outlined in Good Medical Practice. ${ }^{1}$

1. Make sure the patient is told in writing of your decision to end the professional relationship, and your reasons for doing so.

2. Record your decision to end the professional relationship in the patient records, in a manner that does not limit the patient's future treatment. 
3. Make sure arrangements are made promptly for the continuing care of the patient and pass on the patient's records without delay.

4. Be prepared to justify your decision.

\section{CONCLUSION}

We are constantly reminded as clinicians to maintain a professional boundary with our patients. Although rare we are informed or talk about strategies in dealing with advances from the patient's side, such advances can hamper the reputation of a doctor and put their medical practice at risk. Here I have outlined some strategies to integrate within our practice, in order to avoid potential medico- legal proceedings. Medical educationists should consider developing workshops to better prepare clinicians for such scenarios. It would be of interest to hear from readers about similar experiences, comments, opinions and views.

\section{REFERENCES}

1. General Medical Council (2013). Good medical practice. Available at: https://www.gmc-uk.org/ guidance/good_medical_practice.asp (accessed 28.2.18)

\title{
Toxic Shock Syndrome: Case Report
}

\author{
Dr Samuel Mercer CT2
}

\section{SUMMARY}

The case report focuses on a case that the author saw in winter 2016. It focuses on a case of a young lady who presented with profound sepsis. Initially thought to have a tropical medicine aetiology, as the patient had recently visited Latin America, on further examination of the patient it was found that an old tampon was the cause. A diagnosis of toxic shock syndrome was then made. This case will discuss toxic shock syndrome in more detail.

\section{BACKGROUND}

We are well versed in hospitals of being told to think about sepsis. There have been numerous campaigns trying to assist clinicians in making the diagnosis early and the importance of this. ${ }^{1}$ However, clinicians may not always be aware of the more severe forms of sepsis. The author himself was not aware of toxic shock syndrome until he encountered this particular patient.

Toxic shock syndrome is a toxin mediated life-threatening ailment. It is usually mediated by Staphylococcus aureus or group A streptococcus, sometimes call Streptococcus pyogenes. ${ }^{2}$ Thankfully it is rare with an incidence of 1.5-5.2 cases per 100,000 annually. ${ }^{3}$ Toxic shock has often been associated with tampon use. Though it is true that tampon use is a recognised risk factor, it was actually first described in children in $1978 .{ }^{4}$ Indeed 50\% of cases are not associated with menstruation.

The basic pathophysiology is that the toxins involved in toxic shock syndrome produce super antigens. Whilst normal antigens only activate $0.01 \%$ of the $\mathrm{T}$ cell population, super antigens activate around $5-30 \%$ of the $\mathrm{T}$ cell population. The effect of this is a large production of cytokines that in turn mediate shock and tissue injury. ${ }^{5}$ As this case report shall show, the patient was significantly unwell and it is hoped that by reading this article, physicians will be more aware of this life-threatening condition.

\section{CASE PRESENTATION}

On a busy winter day a lady in her 20's was seen in an overflowing resuscitation department at a district general hospital in the North of England. She had been brought in by her partner with the complaint of headache, fever and diarrhoea. The symptoms had been ongoing for two days. Her partner had become increasingly concerned about the patient due to her decreasing levels of consciousness. No one else in the shared house where the patient lived was unwell.

Past medical history included scoliosis but nil else of note. There was no documentation of the patient having been admitted to the current hospital previously. No surgical history of note was elicited.

Social history included that the patient was a social sciences student who had two months ago come back from an expedition in Central America. There was no history of narcotic use or tobacco use. Alcohol use was occasional and there was no history of recent alcohol consumption. Drug history included the oral contraceptive pill but nothing else, with a documented allergy to amoxicillin.

Unfortunately, the patient was not communicative enough to give a full family history, but there was no mention of anything sinister in the family history.

\section{INVESTIGATION AND EXAMINATION}

On examination the patient's airway was patent; there was good air entry throughout the lungs, although the respiratory rate was 40 and oxygen saturation $97 \%$ on room air. Blood pressure was $87 / 32$ after $1.5 \mathrm{~L}$ of IV fluids with a sinus pulse of 116 . Heart sounds were normal and an ECG showed a sinus tachycardia.

Neurologically the patient had a GCS of 14/15 E5 M6. Blood sugar was 7.1. Due to the patient's rather drowsy state a full intensive neurological exam was not possible. However, planters were down going, no photophobia could be elicited and no neck stiffness was found. Power was also $5 / 5$ all 4 limbs. 